\title{
Congenital intrapericardial aneurysms of the left atrium
}

\author{
U. TH A D A N I, W. WH I T A K E R, \\ a n d D. A. W A T S O N
}

The Department of Cardiology and Cardiothoracic Surgery, The General Infirmary at Leeds

\begin{abstract}
Thadani, U., Whitaker, W., and Watson, D. A. (1975). Thorax, 30, 102-109. Congenital intrapericardial aneurysms of the left atrium. A patient with congenital intrapericardial aneurysm/diverticulum of the left atrium diagnosed preoperatively is described. A review of the 16 previously reported cases revealed that the majority of the patients present with palpitation and are found to have an abnormal cardiac shadow on chest radiography, as did this patient. The aneurysm appears to cause systemic emboli and paroxysmal or persistent atrial tachyarrhythmias which are often resistant to medical therapy. The presence of the aneurysm is suggested by an abnormal contour of the left cardiac border in the postero-anterior chest radiograph and this can be confirmed by angiocardiography. Surgical excision of the aneurysm is indicated in all patients to prevent the occurrence or recurrence of systemic emboli and atrial arrhythmias. Our patient has remained free of symptoms since her operation 14 months ago.
\end{abstract}

Localized intrapericardial aneurysms of the left atrial wall or appendage are uncommon in the absence of mitral valve disease and have usually been recognized only after an exploratory thoracotomy. A patient with this congenital anomaly, observed over a period of ten years and recognized preoperatively, is now described. The diagnosis and management of this lesion, which appears to cause systemic emboli (Palacio et al., 1960; Parmley, 1962; Williams, 1963; Behrendt and Aberdeen, 1972; Eie et al., 1972) and paroxysmal or persistent atrial tachyarrhythmias (Semans and Taussig, 1938; Palacio et al., 1960; Parmley, 1962; Pitts and Potts, 1962; Parker, Connell, and Lynn, 1967; Saint-Florent et al., 1967; Godwin et al., 1968; Varghese et al., 1969; MacLeod et al., 1970; Sanderud et al., 1971; Eie et al., 1972; Hansen, Rygg, and Efsen, 1974), which may prove refractory to medical treatment (Parker et al., 1967; Godwin et al., 1968; Varghese et al., 1969; MacLeod et al., 1970; Eie et al., 1972; Hansen et al., 1974), are discussed and the literature is reviewed.

\section{CASE REPORT}

A housewife, aged 23, first presented in January 1964, complaining of localized left precordial pain of three months' duration. This was non-specific in character and unrelated to exercise. Clinical examination then revealed no abnormality. There was sinus rhythm, a systemic blood pressure of $105 / 65 \mathrm{mmHg}$, and normal heart sounds. The electrocardiogram showed a deep $S$ wave $(35 \mathrm{~mm})$ in lead $V_{2}$ but was otherwise unremarkable. The chest radiograph (Fig. 1a) showed an abnormal left cardiac border and bilateral basal pulmonary opacities suggestive of underlying basal bronchiectasis. As the patient was pregnant, cardiac catheterization and angiographic studies were not done. She went to term without complications and gave birth to a normal child. When she attended for a postnatal review she was well and there was no change in physical, electrocardiographic or radiological signs. At that time a clinical diagnosis of a dilated left atrial appendage was made. She seemed too fit to be investigated further and was discharged to the care of her general practitioner.

She had two further pregnancies during which there were no cardiological problems. In September 1971, during the second trimester of her fourth pregnancy, she was admitted as an emergency to Pinderfields General Hospital on account of breathlessness on exertion and dizziness. She was found to have atrial fibrillation and was treated with digoxin and anticoagulants until March 1972. She went to term and gave birth to a normal child but her symptoms persisted and she was then referred back to the cardiological clinic. In July 1972, her main symptoms were exertional dyspnoea, palpitation, and dizziness. On examination there was atrial fibrillation, 


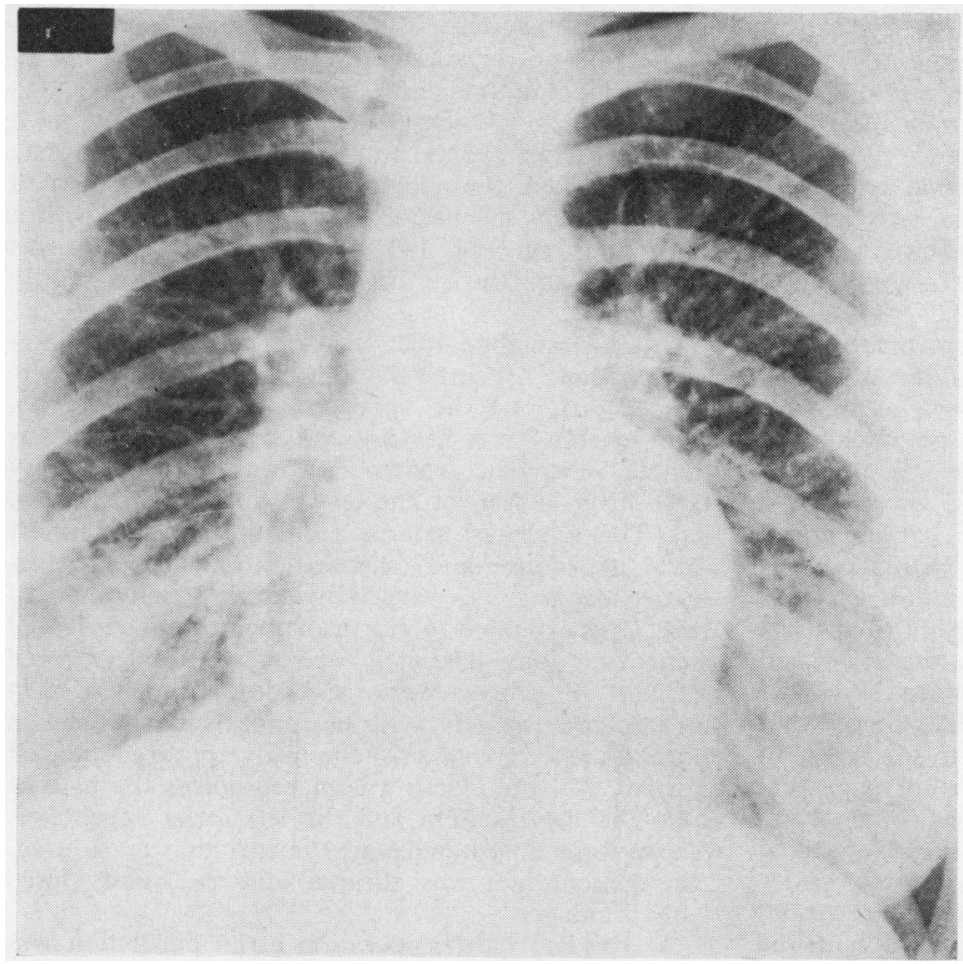

(a)

FIG. 1. Preoperative posteroanterior chest radiographs: (a) taken in January 1964, showing a bulge on the left cardiac border and basal pulmonary changes; (b) taken in July 1972, showing considerable increase in heart size.

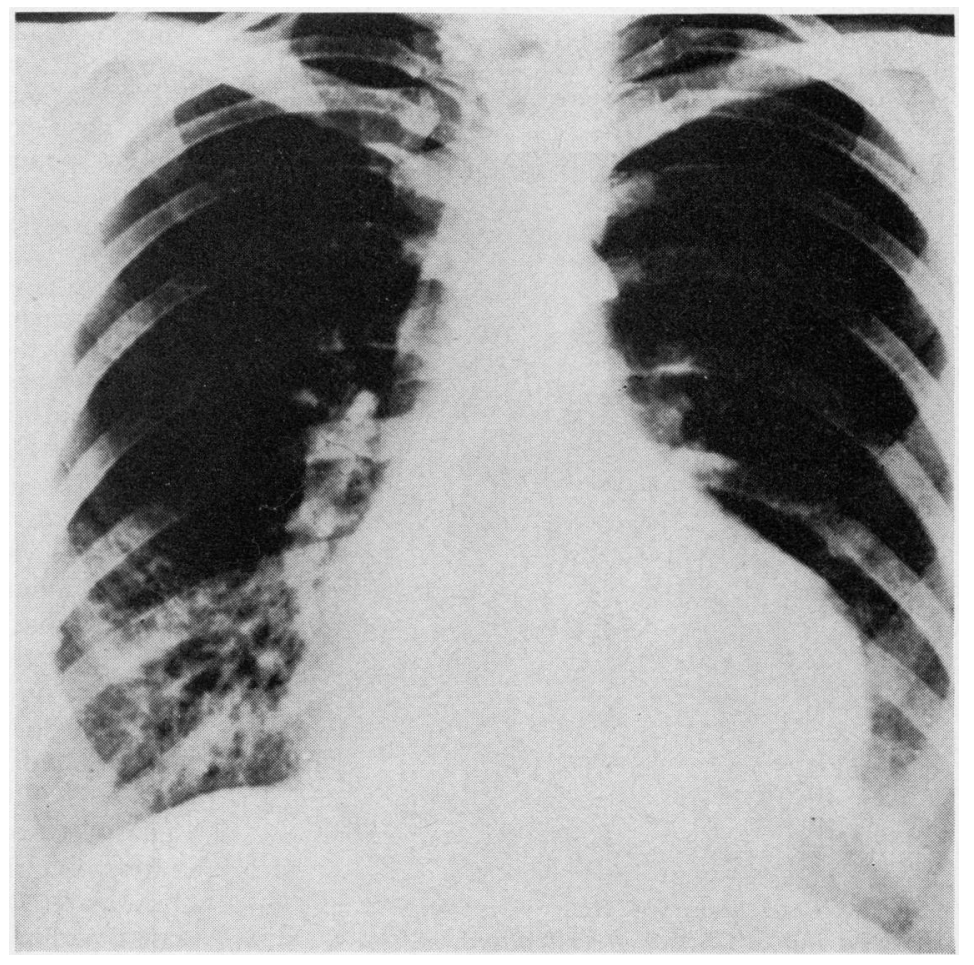


no cardiac enlargement, variable heart sounds but no murmurs. The chest was clear. The electrocardiogram showed atrial fibrillation with a ventricular rate of 72 per minute. The chest radiograph (Fig. 1b) showed that the heart had enlarged since 1964, but the appearances at the lung bases had not changed.

In view of the patient's symptomatic deterioration and changes in the radiological appearance, she was admitted to hospital in November 1972 for haemodynamic and angiographic studies with a provisional diagnosis of cardiac tumour or cardiomyopathy.

Right and left cardiac catheterization was performed on 7 November 1972. There were no pressure gradients across the aortic, mitral, pulmonary or tricuspid valves, and all the pressures were normal at rest and during supine leg-raising exercise. No intracardiac shunt was detected. The cardiac index at rest was reduced to $1.6 \mathrm{l} / \mathrm{min} / \mathrm{m}^{2}$. A biplane left ventricular angiogram revealed a most unusual picture in that there appeared to be a mass lying to the left of the left ventricle, displacing it to the right and elongating its outflow tract. A biplane right ventricular angiogram was performed which showed that the right ventricle was also displaced to the right. In the late films a normal sized left atrium appeared, and shortly afterwards a very large cavity lying above and to the left of the ventricle opacified (Fig. 2) and was slow to clear. This abnormal cavity was considered to be a diverticulum of the left atrium since it clearly had no direct communication with the left ventricle and was thin-walled.

The presence of incapacitating symptoms, atrial fibrillation, progressive cardiac enlargement, and the risk of systemic emboli were considered indications

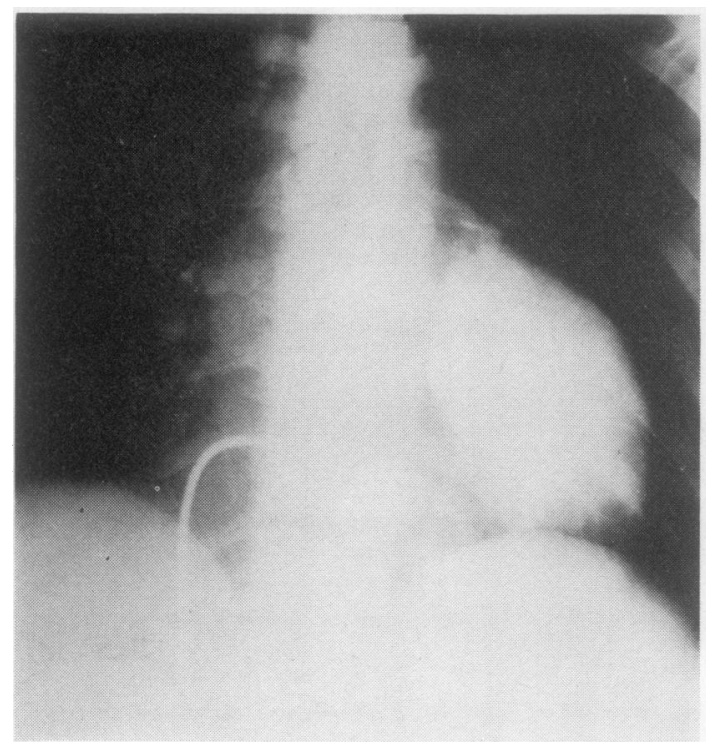

FIG. 2. Late phase of right ventricular angiogram showing the left atrial diverticulum. for surgical excision of the left atrial diverticulum. While waiting for surgery the patient complained of bouts of palpitation and during one of these had a transient loss of consciousness, probably due to a rapid ventricular rate and a further fall in cardiac output. When the electrocardiogram was repeated preoperatively she had rapid atrial fibrillation with a ventricular rate of 140 per minute, but she was digitalized and the ventricular rate was satisfactorily controlled.

On 7 December 1972 the left atrial diverticulum was excised. An anterolateral thoracotomy was performed stripping the upper border of the fifth rib. The left lung was healthy and the pericardium was intact. When the pericardium was opened, a very large diverticulum of the left atrium presented (Fig. 3a). This appeared to arise from the base of the left atrial appendage and extended downwards and forwards where it was very thin-walled. It had a broad base, approximately $6 \mathrm{~cm}$ in diameter, and measured some $8 \mathrm{~cm}$ long. The atrial appendage itself appeared normal. Pressures were recorded from the left atrium and the left ventricle and these were again normal. The remainder of the heart appeared and felt normal. A large clamp was placed across the base of both the diverticulum and the left atrial appendage. These were amputated and the atrium was sutured. The pericardium was sutured and the chest closed with drainage.

At the end of the operation atrial fibrillation was converted to sinus rhythm by means of a single synchronized DC shock of 100 joules, and treatment with digoxin was discontinued.

The postoperative course, apart from the development of a transient pericardial effusion which regressed spontaneously, was quite uneventful. When last seen as an outpatient on 20 February 1974 the patient was symptom-free and in sinus rhythm and the chest radiograph (Fig. 4) showed a normal cardiac silhouette with a persistence of basal pulmonary changes. Subsequent bronchography confirmed that the basal pulmonary changes were due to underlying basal bronchiectasis.

The pathological findings were reported as follows by Dr. T. W. Sutherland: 'The specimen consists of a part of an atrium, approximately $9 \times 5 \times 3 \mathrm{~cm}$. The inner surface shows a vertical myocardial ridge which separates less altered atrial wall $5 \times 2 \mathrm{~cm}$ with a normal looking endocardial surface from thinned atrial wall $6.5 \mathrm{~cm}$ vertically and $5 \mathrm{~cm}$ transversely, representing the diverticulum (Fig. 3b). The diverticulum is patchily semi-translucent and in parts shows a finely trabeculated inner surface. No thrombus can be detected. The atrial appendage seems slightly hypertrophied but not dilated.

Microscopically sections of the diverticulum show parts where the wall is wholly composed of dense collagen without elastica or myocardial 


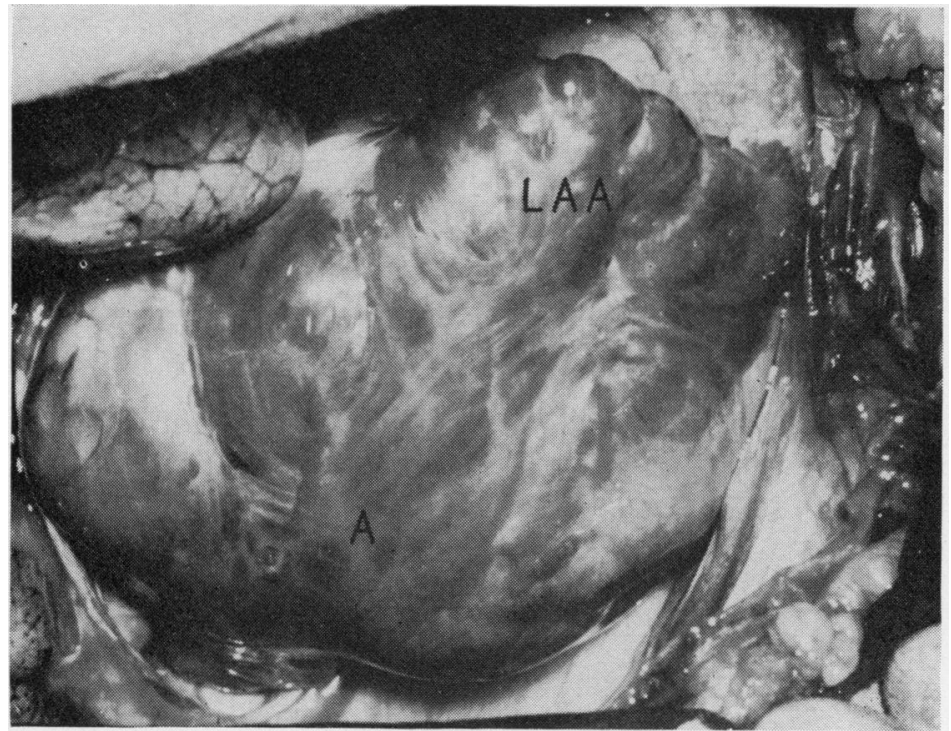

(a)

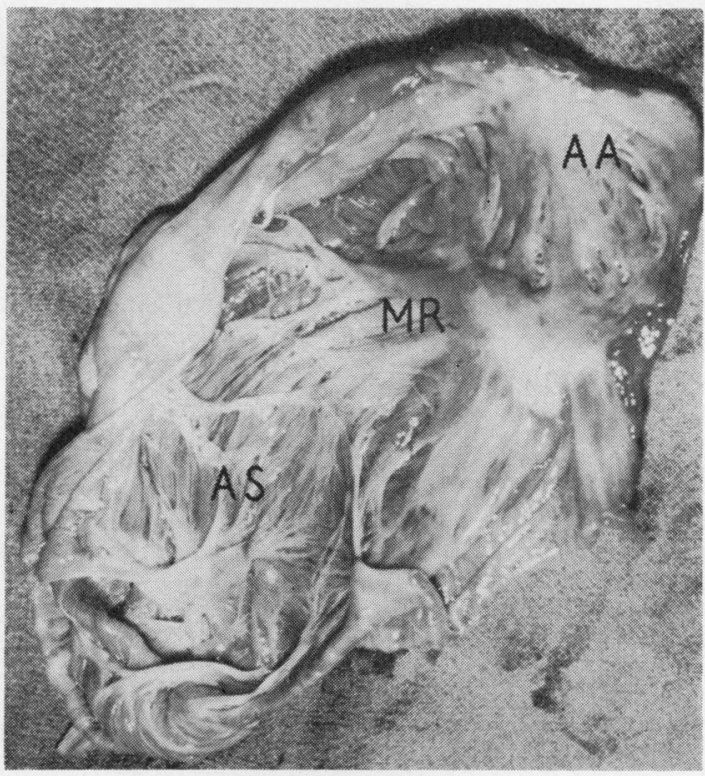

(b)

FIG. 3. (a) Shows appearances at operation with the pericardium opened. There is a thin-walled and tense left atrial aneurysm $(A)$ and left atrial appendage $(L A A)$. (b) Shows inner surface of the aneurysm and the left atrial appendage: $A A$-atrial appendage; $A S$-aneurysmal sac; $M R-$ myocardial ridge. 


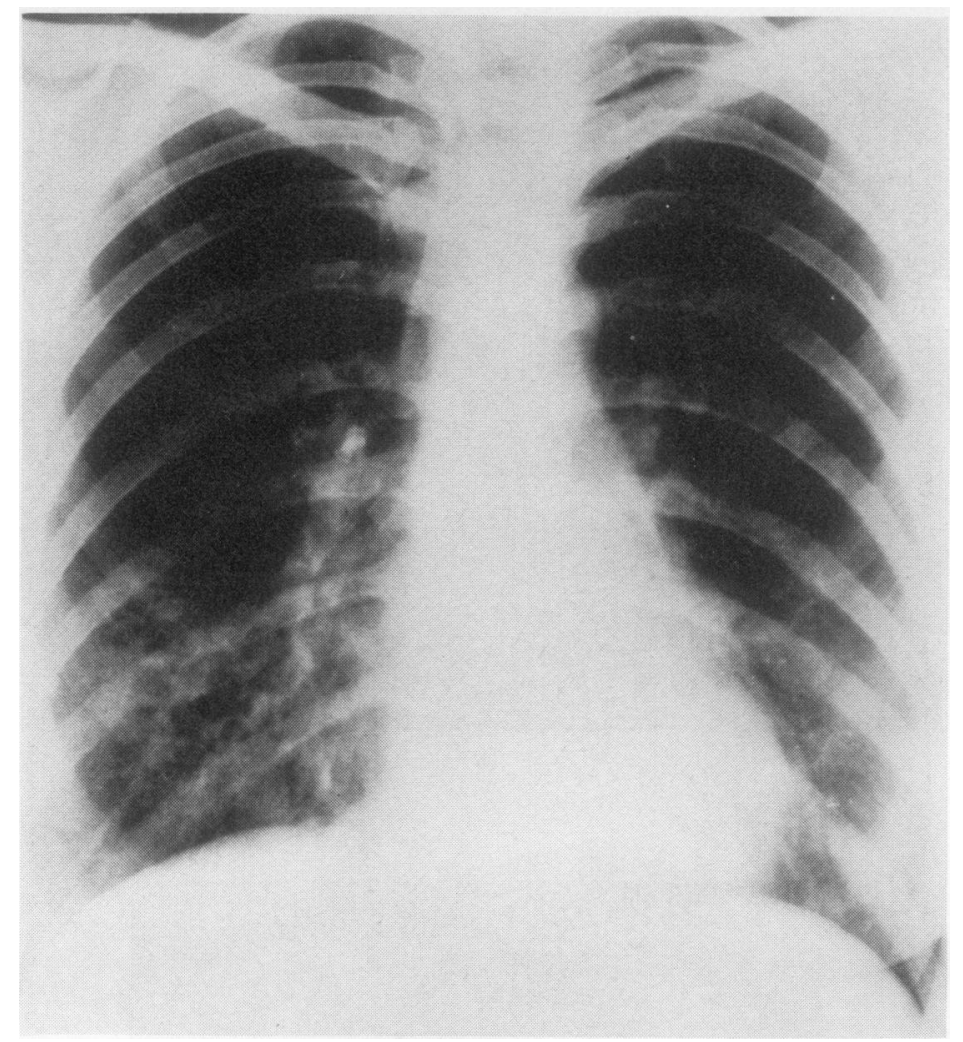

FIG. 4. Postoperative postero-anterior chest radiograph taken in February 1974 showing normal cardiac silhouette and basal pulmonary opacities due to underlying basal bronchiectasis.

fibres. In other parts myocardial fibres seem slightly hypertrophied and are associated with a thick fibrotic subendocardial stroma, rich in laminae of elastic. No Alcian blue stained substance can be detected.

No intrinsic inflammatory, vascular or neoplastic disease can be detected to account for the formation of the diverticulum.'

\section{DISCUSSION}

Mitral valve disease is a common cause of aneurysmal dilatation of the left atrium, and saccular aneurysms of the left atrium following injury to the atrial wall or secondary to inflammatory or circulatory disturbances have also been documented (Lutembacher, 1917 and 1918; Bramwell and Duguid, 1927). However, true congenital aneurysms involving part of the left atrium or its appendage are rare. The first case was recorded by Semans and Taussig (1938), who described the necropsy findings in a 5-year-old negro girl. She presented with congestive cardiac failure, ectopic tachycardia, and cardiomegaly. She had thin-walled intrapericardial saccular aneurysm of the left atrium, incomplete dextrocardia, thickening of the mitral and tricuspid valve leaflets, and an abnormally small circumflex branch of the left coronary artery. Histological examination failed to reveal any inflammatory or fibrotic reaction. Following this account, 15 further examples of intrapericardia aneurysms of the left atrium were reported and these, together with the present case, are summarized in the Table. Three other patients (Froment et al., 1967; Sloman, Hunt, and Hare, 1969; Salonikides et al., 1970), who on angiographic studies were thought to have this lesion but in whom the condition of the pericardium was not stated, are not included in further discussion.

When these reported cases are analysed together with the present patient it is obvious that the clinical and radiological appearances and the 
T A B L E

SUMMARY OF PREVIOUS CASE REPORTS AND PRESENT CASE

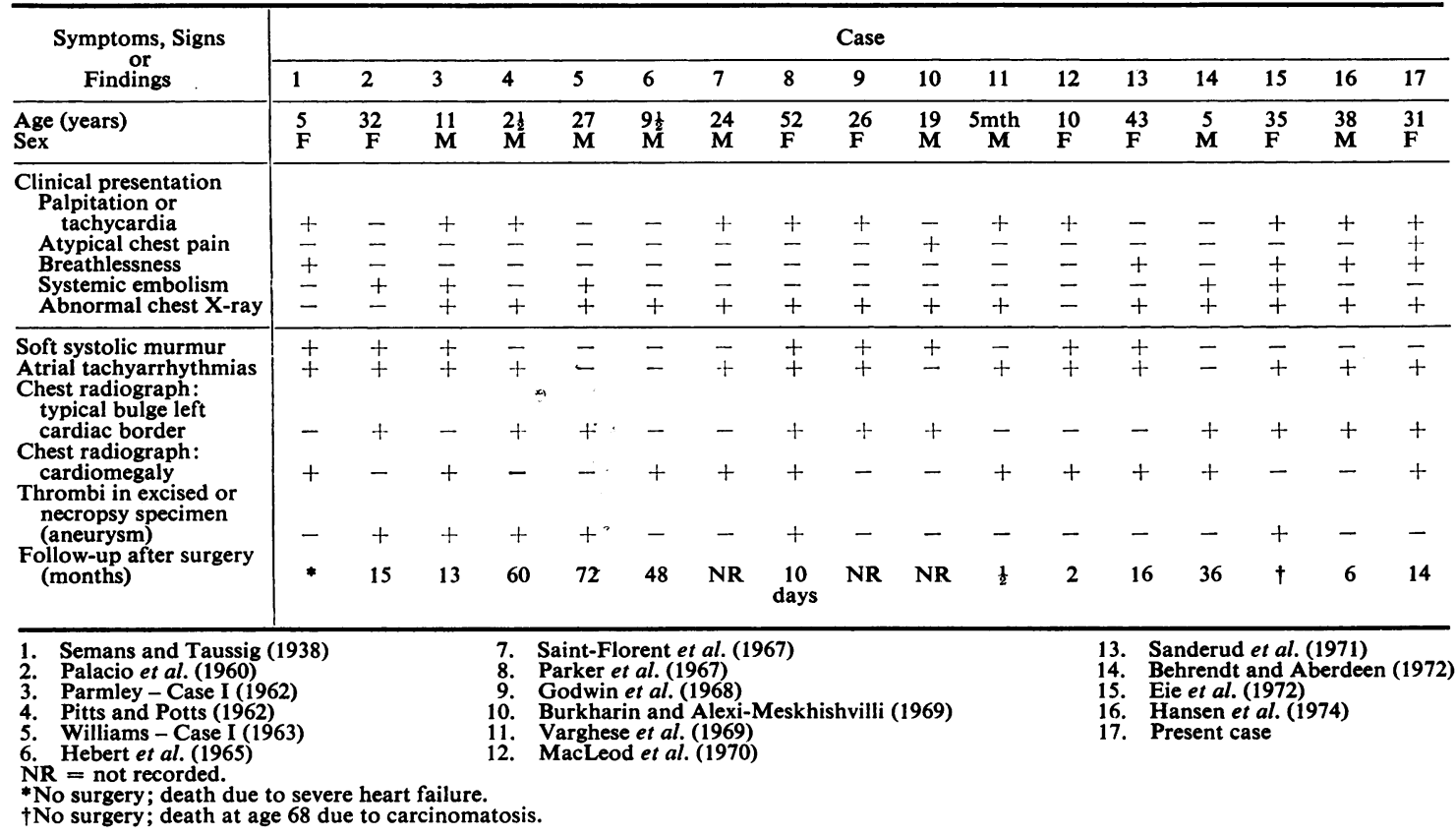

complications of intrapericardial aneurysms arising from the left atrial wall or appendage have much in common. These are lesions which must be considered in all patients who have abnormal left cardiac shadows, particularly if they present with attacks of palpitation. Nine of the 16 reported cases (Palacio et al., 1960; Pitts and Potts, 1962; Williams, 1963; Parker et al., 1967; Godwin et al., 1968; Burkharin and Alexi-Meskhishvilli, 1969; Behrendt and Aberdeen, 1972; Eie et al., 1972; Hansen et al.,1974) and our own had unusually shaped hearts (Fig. 1) and yet a correct preoperative diagnosis was made in only five (Parker et al., 1967; Godwin et al., 1968; Eie et al., 1972; Hansen et al., 1974) including our patient. Most of these patients have been wrongly diagnosed as having cardiac or mediastinal tumours (Pitts and Potts, 1962; Williams, 1963; Hebert et al., 1965; Saint-Florent et al., 1967; MacLeod et al., 1970; Behrendt and Aberdeen, 1972), left ventricular aneurysms (Palacio et al., 1960; Behrendt and Aberdeen, 1972; Eie et al., 1972) or pericardial cyst (Burkharin and Alexi-Meskhishvilli, 1969). If the lesion is suspected, angiocardiography offers the means of obtaining confirmatory evidence (Parmley, 1962; Parker et al., 1967; Godwin et al., 1968; Varghese et al., 1969; Sanderud et al., 1971; Eie et al., 1972; Hansen et al., 1974).
Paroxysmal attacks of palpitation and paroxysmal supraventricular tachycardia, atrial flutter, and atrial fibrillation occurred in 11 of the reported cases (Semans and Taussig, 1938; Palacio et al., 1960; Parmley, 1962; Pitts and Potts, 1962; Parker et al., 1967; Saint-Florent et al., 1967; Godwin, et al., 1968; Varghese et al., 1969; MacLeod et al., 1970; Eie et al., 1972; Hansen et al., 1974). Our patient and the case reported by Sanderud and his colleagues (1971) developed persistent atrial fibrillation. Some of these arrythmias have been resistant to medical treatment (Parker et al., 1967; Godwin et al., 1968; Varghese et al., 1969; MacLeod et al., 1970; Eie et al., 1972; Hansen et al., 1974), but following surgical excision of the aneurysm the arrhythmias have not recurred even when drug therapy has been stopped (Palacio et al., 1960; Parmley, 1962; Pitts and Potts, 1962; Parker et al., 1967; Varghese et al., 1969; MacLeod et al., 1970; Sanderud et al., 1971; Hansen et al., 1974). In the present case sinus rhythm was restored after a DC shock and atrial fibrillation has not recurred during 14 months follow-up. From these observations it would appear that an ectopic focus located in the aneurysm and associated with a re-entry phenomenon is responsible for the initiation of an atrial arrhythmia. This hypothesis is further supported 
by the observation that two patients, one with a left aneurysm (Hansen et al., 1974) and the other with a right atrial aneurysm (Morrow and Behrendt, 1968), reverted from atrial fibrillation to sinus rhythm on clamping the anuerysmal sac at surgery.

Patients with congenital aneurysms of the left atrium appear to be at risk from systemic emboli. These occurred in five of the reported cases (Palacio et al., 1960; Parmley, 1962; Williams, 1963; Behrendt and Aberdeen, 1972; Eie et al., 1972), and in four of these (Palacio et al., 1960; Parmley, 1962; Williams, 1963; Eie et al., 1972) and in two others (Pitts and Potts, 1962; Parker et al., 1967), thrombus was present in the excised aneurysm. Williams' patient is of special interest in that the aneurysm was not excised when discovered at the first thoracotomy. Two years later, after the patient had presented with a cerebral embolism, a thrombus was found in the left atrial appendage when the aneurysm was excised. Similarly, the patient described by Eie and his colleagues who refused surgery experienced five episodes of peripheral embolism. Thirty-three years later the patient died of carcinomatosis, and thrombi were found in the left atrial aneurysm.

Some congenital aneurysms of the left atrial appendage are associated with a pericardial defect (Fry, 1953; Dimond, Kittle and Voth, 1960; Hering, Wilson, and Ball, 1960; Williams Case 2, 1963). These are similar to congenital intrapericardial aneurysms in radiological appearance and also have not often been diagnosed preoperatively, but they, in contrast, do not appear to be associated with atrial arrhythmias or systemic emboli and may present with chest pain, which is thought to be due to the appendage being trapped (Hering et al., 1960; Williams Case 2, 1963). The induction of artificial pneumothorax has been used to demonstrate an associated pericardial defect when present (Ellis, Leeds, and Himmelstein, 1959; Hering et al., 1960; Fowler, 1962; Pernot et al., 1972).

In the published reports and in the present case there was no evidence of any acquired inflammatory reaction or circulatory disturbance which could have caused the aneurysm to develop. They are probably congenital in origin, and associated anomalies have occurred in some of the reported cases (Semans and Taussig, 1938; Parmley, 1962; Varghese et al., 1969; Behrendt and Aberdeen, 1972). It is impossible to say whether or not the bilateral bronchiectasis in the present case is congenital in origin. Similarly, it is only specula- tive that the presence of fibroelastic tissue in the aneurysmal sac in the present and four previously reported patients (Williams, 1963; Hebert et al., 1965; Parker et al., 1967; Behrendt and Aberdeen, 1972) represents a congenital anomaly or plays a significant role in the causation of these aneurysms.

The recorded case and that described by Parker et al. (1967) illustrate that there can be progressive enlargement of the aneurysmal sac (Fig. 1b) and this presumably precipitates atrial arrhythmias and leads to clot formation.

In patients with a history of arrhythmia or systemic embolus surgical excision of the aneurysm is essential and would seem to be indicated to prevent these complications in any who are otherwise diagnosed, for example after radiological examination. There has been no mortality in any of the patients surgically treated.

We are grateful to Dr. C. A. Johnson, of the Department of Russian Studies, and Dr. A. J. Reyes, of the Cardiovascular Unit, University of Leeds, for translation of the articles.

\section{REFERENCES}

Behrendt, D. M. and Aberdeen, E. (1972). Congenital aneurysm of the left atrium. Annals of Thoracic Surgery, 13, 54.

Bramwell, J. C. and Duguid, J. B. (1927). Aneurysmal dilatation of the left auricle. Quarterly Journal of Medicine, 21, 187.

Burkharin, V. A. and Alexi-Meskhishvilli, V. V. (1969). Congenital aneurysmal distension of the left auricular appendage. Grudnaia Khirurgiia (Moskva), 11, No. 6, 93.

Dimond, E. G., Kittle, C. F., and Voth, D. W. (1960). Extreme hypertrophy of the left atrial appendage. The case of the giant dog ear. American Journal of Cardiology, 5, 122.

Eie, H., Semb, G., Muller, O., and Holm, H. A. (1972). Aneurysm of the left atrial appendage. Scandinavian Journal of Thoracic and Cardiovascular Surgery, 6, 149.

Ellis, K., Leeds, N. E., and Himmelstein, A. (1959). Congenital deficiencies in the parietal pericardium. A review with two new cases including successful diagnosis by plain roentgenography. American Journal of Roentgenology, 82, 125.

Fowler, N. O. (1962). Congenital defect of the pericardium; its resemblance to pulmonary artery enlargement. Circulation, 26, 114.

Froment, R., Loire, R., Dalloz, Cl., and Age, C. (1967). "Hernie congénitale" de l'auricule gauche avec ou sans dehiscence péricardique. Archives des Maladies du Coeur et les Vaisseaux, 60, 1476.

Fry, W. (1953). Herniation of the left auricle. American Journal of Surgery, 86, 736. 
Godwin, T. F., Auger, P., Key, J. A., and Wigle, E. D. (1968). Intrapericardial aneurysmal dilatation of the left atrial appendage. Circulation, 37, 397.

Hansen, J. F., Rygg, I., and Efsen, F. (1974). Intrapericardial left atrial aneurysm. American Heart Journal, 87, 113.

Hebert, W. M., Arismendi, L., Ruhstaller, F. D., and Petersen, H. C. (1965). Aneurysm of the left atrium associated with syncope and cyanosis. Journal of Thoracic and Cardiovascular Surgery, 49, 535.

Hering, A. C., Wilson, J. S., and Ball, R. E. (1960). Congenital deficiency of the pericardium. Journal of Thoracic and Cardiovascular Surgery, 40, 49.

Lutembacher, R. (1917). Anévrysme de l'oreillette gauche, contribution á l'étude du rhythme bigéminé. Archives des Maladies du Coeur et des Vaisseaux, 10, 145.

(1918). Deux nouveaux cas d'anévrysme de l'oreillette gauche. Archives des Maladies du Coeur et des Vaisseaux, 11, 434.

MacLeod, C. A., Ankeney, J. L., Perrin, E. V., Nickel, S. S., and Leibman, J. (1970). Left atrial aneurysm. American Heart Journal, 80, 683.

Morrow, A. G. and Behrendt, D. M. (1968). Congenital aneurysm (diverticulum) of the right atrium. Circulation, 38, 124.

Palacio, J., Guido, J. J., Noger, V. N., Gonnella, C. G., and Villegas-Videla, A. F. (1960). Megaorejuela izquierda congenita. Le Prensa Medica Argentina, 47, 1505.

Parker, J. O., Connell, W. F., and Lynn, R. B. (1967). Left atrial aneurysm. American Journal of Cardiology, 20, 579.

Parmley, L. F. (1962). Congenital atriomegaly. Circulation, 25, 553.
Pernot, C., Hoeffel, J. C., Henry, M., Frisch, R., and Brauer, B. (1972). Partial left pericardial defect with herniation of the left atrial appendage. Thorax, 27, 246.

Pitts, R. M. and Potts, W. J. (1962). Congenital diverticulum of the left atrium. Archives of Surgery, 84, 334.

Saint-Florent, G.de., Duboys, Y., Neveux, J. Y., and Mathey, J. (1967). Anévrysme congénital de l'auricule. Annales de Chirurgie Thoracique et Cardio-Vasculaire, 6, 110.

Salonikides, N., Tsakonas, P., Gazetopoulos, N., Katsonis, S., and Manes, M. (1970). Dilatation aneurysmale congénitale de l'auricule gauche. Acta Cardiologica, 25, 188.

Sanderud, A., Garman, D., Hatle, L., and Rokseth, R. (1971). Aneurysmal dilatation of the left auricle. Scandinavian Journal of Thoracic and Cardiovascular Surgery, 5, 143.

Semans, J. H. and Taussig, H. B. (1938). Congenital "aneurysmal" dilatation of the left auricle. Bulletin of the Johns Hopkins Hospital, 63, 404.

Sloman, G., Hunt, D., and Hare, W. S. C. (1969). Aneurysmal dilatation of the left atrial appendage. Medical Journal of Australia, 2, 101.

Varghese, P. J., Simon, A. L., Rosenquist, G. C. Berger, M., Rowe, R. D., and Bender, H. W. (1969). Multiple saccular congenital aneurysms of the atria causing persistent atrial tachyarrhythmia in an infant. Paediatrics, 44, 429.

Williams, W. G. (1963). Dilatation of the left atrial appendage. British Heart Journal, 25, 637.

Requests for reprints to: D. A. Watson, F.R.C.S., The Department of Cardiology and Cardiothoracic Surgery, The General Infirmary, Leeds. 